\title{
Pregnancy after bariatric surgery: improving outcomes for mother and child
}

\author{
This article was published in the following Dove Press journal: \\ International Journal of Women's Health \\ 14 December 2016 \\ Number of times this article has been viewed
}

\author{
Irene González' \\ Albert Lecube ${ }^{2}$ \\ Miguel Ángel Rubio 3 \\ Pedro Pablo García-Luna ${ }^{4}$ \\ 'Endocrinology and Nutrition \\ Department, Complejo Hospitalario \\ Universitario de Huelva, Huelva, \\ Spain; ${ }^{2}$ Endocrinology and \\ Nutrition Department, Arnau de \\ Vilanova University Hospital, Lleida \\ Biomedicine Research Institute \\ (IRB-Lleida), CIBER in Diabetes and \\ Associated Metabolic Disorders \\ (CIBERDEM), Lleida University, \\ Lleida, Spain; ${ }^{3}$ Endocrinology and \\ Nutrition Department, Hospital \\ Clínico San Carlos, IDISSC, Madrid, \\ Spain; ${ }^{4}$ Endocrinology and Nutrition \\ Department, Hospitales Universitarios \\ Virgen del Rocío, Seville, Spain
}

\begin{abstract}
The significant increase in the prevalence of obesity has led to an increase in the number of obese women who become pregnant. In this setting, in recent years, there has been an exponential rise in the number of bariatric procedures, with approximately half of them performed in women of childbearing age, and a remarkable surge in the number of women who become pregnant after having undergone bariatric surgery (BS). These procedures entail the risk of nutritional deficiencies, and nutrition is a crucial aspect during pregnancy. Therefore, knowledge and awareness of the consequences of these techniques on maternal and fetal outcomes is essential. Current evidence suggests a better overall obstetric outcome after BS, in comparison to morbid obese women managed conservatively, with a reduction in the prevalence of gestational diabetes mellitus, pregnancy-associated hypertensive disorders, macrosomia, and congenital defects. However, the risk of potential maternal nutritional deficiencies and newborns small for gestational age cannot be overlooked. Results concerning the incidence of preterm delivery and the number of $\mathrm{C}$-sections are less consistent. In this paper, we review the updated evidence regarding the impact of BS on pregnancy.
\end{abstract}

Keywords: bariatric surgery, pregnancy, maternal and fetal outcomes, gestational diabetes mellitus, small for gestational age

\section{Introduction}

In recent years, there has been a significant increase in the number of obese women who become pregnant; in fact, obesity has currently become one of the most important gestational risk factors. Gestational obesity is considered when body mass index (BMI) is $\geq 30 \mathrm{~kg} / \mathrm{m}^{2}$ at the first obstetric evaluation. Obesity should be considered a chronic disease, especially in the context of morbid obesity, and so therapeutic approaches should be directed to women of childbearing age before they become pregnant, during pregnancy, and in the postpartum period. So, women should schedule their pregnancies, and try to achieve an optimal body weight before conceiving, to avoid potential obstetric complications arising from obesity, including gestational diabetes mellitus (GDM), hypertension, complications in delivery, increased rates of $\mathrm{C}$-sections, macrosomia, and congenital defects, among others. ${ }^{1}$

Management of obesity is complex and involves multiple variables, with sometimes limited efficacy of the conservative approach. In this setting, bariatric surgery (BS) emerged as a promising approach for those cases where previous treatments failed; specifically, it implies a net negative energy balance, enabling subsequent effective and lasting weight loss. Bariatric procedures can be classified into two groups depending on whether the main mechanism involved in weight loss is restriction or malabsorption. Pure restrictive techniques include the adjustable gastric band (AGB) and laparoscopic vertical sleeve gastrectomy. Malabsorptive weight loss procedures

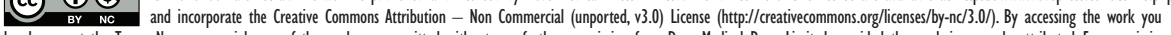
hereby accept the Terms. Non-commercial uses of the work are permitted without any further permission from Dove Medical Press Limited, provided the work is properly attributed. For permission for commercial use of this work, please see paragraphs 4.2 and 5 of our Terms (https://www.dovepress.com/terms.php).

Correspondence: Albert Lecube Endocrinology and Nutrition Department, Arnau de Vilanova Roure 80, 25198 Lleida, Spain

$\mathrm{Tel}+34973705$ I 83

submit your manuscript $\mid$ www.dovepress.com 
are mainly biliopancreatic diversion (BPD). Recently, endoscopic specialists and surgeons have developed new intraluminal/endoscopic techniques in the treatment of obesity, with less clinical risks and economic costs, while maintaining the benefits in terms of morbidity and mortality. ${ }^{2}$ Roux-en-Y gastric bypass (RYGB) is still considered the gold standard, since it combines both restrictive and malabsorptive effects, allowing for optimum efficacy of combined weight loss, without severe nutrient and vitamin deficiencies, which can develop after pure malabsorptive techniques. With the increase in the number of bariatric procedures performed over the last decade, about half of them in women of childbearing age, a remarkable increase in the number of women who get pregnant after undergoing BS has also occurred. ${ }^{3}$

Weight loss has been proven to reduce adverse maternal and perinatal outcomes, and so it could also be hypothesized that BS could achieve the same positive results. However, these procedures entail the risk of nutritional deficiencies, and nutrition is a crucial aspect during pregnancy. In this regard, it is important to be aware of the possible consequences of BS on maternal and fetal outcomes. Furthermore, many women conceive while they are still overweight, so the potential adverse effects of the still existing obesity should be also considered.

The quality assessment of studies evaluating the effect of BS on fertility, pregnancy, and maternal and perinatal outcomes is essential for proper understanding. However, these studies are scarce, and most of them are nonrandomized and based almost exclusively on the analysis of RYGB and AGB. In addition, the selection of study groups, comparability, and the determination of exposure for case-control or interest outcome for the cohort studies remain key issues to properly evaluating the results of each publication and drawing valid conclusions. Thus, most of the results should be interpreted with caution. Finally, there are currently no clinical practice guidelines specifically addressing this issue, so questions regarding the effectiveness, risks, and maternal and perinatal outcomes of BS in pregnant women remain unanswered - so, conclusions should be taken with caution.

\section{Time lapse between BS and pregnancy}

General recommendations advocates ${ }^{46}$ for a prudent waiting period of at least two years after BS to become pregnant. This interval was chosen since the usual duration of the initial period in which a significant and rapid weight loss occurs, and the potential risk of developing nutritional deficiencies is increased, is approximately $12-24$ months. However, no high-quality evidence supported this recommendation.
In recent years, several studies have reported that maternal and perinatal outcomes of pregnancies occurring earlier than 12-18 months after BS were not inferior. ${ }^{4,7-9}$ But in general, in most publications, mean interval between surgery and pregnancy was greater than 18 months, ranging from 21 to 57.4 months..$^{5,6,10,11}$ In this setting, most clinicians will recommend a minimum waiting period of 1 year after BS before attempting pregnancy, to allow stabilization of body weight and to allow correct identification and treatment of any possible nutritional deficiencies that may not be evident during the first months. However, recommendations should be individualized according to specific anthropometric, clinical, and analytical parameters, as well as the patient's reproductive will.

\section{Maternal nutritional issues}

Despite undergoing BS, most women conceive while still being obese. In fact, pregestational BMI was reported to be between 30.3 and $32.4 \mathrm{~kg} / \mathrm{m}^{2}$ in several recent studies, ${ }^{5,6,10,12}$ an issue which could negatively influence obstetric outcomes in comparison to the normal control population. However, results are greatly variable between studies, probably due to the heterogeneity of control groups and the small number of patients reported. In this regard, some studies found no differences in maternal and fetal outcomes, others found better results, and still others identified a poorer outcome regarding rates of GDM, C-sections, and newborn's weight. ${ }^{6,7,13-15}$

Nutritional status and potential adverse effects derived from nutritional deficiencies are two of the most crucial aspects during pregnancy. This is especially relevant in the setting of previous BS. In fact, because nutritional requirements increase during pregnancy, special attention should be paid to proteins, iron, calcium, and folic acid. Even though routine practice after BS includes prescription of long-term vitamin and micronutrient supplements, rates of compliance in pregnant women may be variable, and they usually range between $84.3 \%$ and 93.7\%, according to different publications. ${ }^{5,16,17}$

Very few studies report on the rate of nutrient deficiencies observed during pregnancy in women who underwent BS. In those who do, for instance, rates of anemia were reported as being low, from $0 \%$ to $24.4 \% .^{7,17,18}$ However, no mention of oral supplements was made. In fact, if we consider the reported serum iron and ferritin levels, and if no specific prophylactic oral supplements were taken by women of childbearing age, a significant increase in anemia would be described. ${ }^{19,20}$ Furthermore, some studies have reported the need for intravenous iron supplements, or even blood transfusion, although these cases 
were exceptional, since, in most situations, anemia was mild or moderate, and oral supplements were enough to restore body iron deposits and hemoglobin levels., ${ }^{7,21,22}$ In this context, the current American Guidelines for the management of patients after BS recommend systematic oral administration of iron supplements to all women of childbearing age. ${ }^{23}$

Regarding vitamin B12 and folic acid, a small study of 39 pregnant women who had undergone BS found a rate of deficiency of $53.4 \%$ and $16.1 \%$, respectively. ${ }^{19}$ Even though systematic supplementation of vitamin B12 is also advocated after most bariatric procedures, the authors of this study acknowledged that they only prescribed it if deficiency was evidenced in analytical workup. In another prospective study of pregnant women who had undergone BS, the evaluation of nutritional deficiencies before and during gestation showed that vitamin B12 was the most prevalent deficiency (45\%), even greater than that of iron $(35 \%){ }^{20}$

In a recent publication by our group, iron deficiency was the most prevalent one observed (60.7\% of patients), and it required specific additional supplementation. This was followed by vitamin 25-OH-D3 deficiency in 40.5\% of patients, B12 deficiency in $22.6 \%$, vitamin A in $7.7 \%$, calcium in $6.6 \%$, vitamin $\mathrm{E}$ in $6 \%$ and folic acid in $5.4 \%{ }^{5}$ In another recent prospective study that followed 49 women who got pregnant after BS, progressively decreasing levels of vitamins $\mathrm{A}, \mathrm{D}, \mathrm{B} 12$, and iron were observed over the course of pregnancy, despite correct compliance with oral supplements, before and during gestation. However, no increase in the rate of obstetric complications was reported. ${ }^{24}$

A major concern among clinicians is the potential development of teratogenesis due to fat-soluble vitamin overdose. In this regard, there have been reports of kidney abnormalities in the offspring of women who took between 40,000 and 50,000 U/d of vitamin A during pregnancy. However, daily ingestion of multivitamin tablets that include around 6,000-8,000 U/d of vitamin A do not seem to increase the rate of malformations related to isotretinoine (13-cis retinoic) exposure, and this result is from several long-term case-control studies. ${ }^{25,26}$ For vitamin D, exposure to high doses increased the rate of fetal cardiac malformations, especially aortic stenosis, which has been associated with an intake of 4,000 IU/d. A strict monitoring and biochemical follow-up of pregnant women taking high doses of vitamins A and D significantly minimizes the risk for developing adverse events. On the other hand, insufficient fetal levels of fat-soluble vitamins, although infrequent, should also be avoided, mainly by adequate control of maternal levels of the same. Table 1 summarizes our current recommendations for vitamin and micronutrient supplements in pregnancy after BS and also in the general pregnant population.

The risk of maternal undernutrition or malnutrition after BS should not be overlooked, especially since it involves an increased risk of fetal malnutrition. Specifically, the functional and anatomical gastrointestinal modifications following BS, along with the increased frequency of nausea and vomiting during the first trimester of pregnancy, carry the risk of not being able to fulfill nutritional and caloric daily requirements to ensure an optimal fetal development. In fact, in certain situations, artificial nutritional supplements may be necessary. In this regard, in a study published over 20 years ago, total parenteral nutrition was required in as many as $21 \%$ of pregnancies. ${ }^{27}$ However, nowadays, this is usually

Table I Recommended daily micronutrient intakes for pregnant women, in general, and in those with previous BS

\begin{tabular}{|c|c|c|}
\hline Micronutrient & $\begin{array}{l}\text { Recommended daily intake for pregnant } \\
\text { women in general }\end{array}$ & $\begin{array}{l}\text { Recommended daily intake for pregnant } \\
\text { women with previous BS }\end{array}$ \\
\hline Folic acid & $\begin{array}{l}0.4 \mathrm{mg} \text {, starting I month before conception, } \\
\text { and continued during the first trimester. }\end{array}$ & $\begin{array}{l}\text { The same as for pregnant women in general. } \\
\text { In obese pregnant women: } 5 \mathrm{mg} \text {. }\end{array}$ \\
\hline $\begin{array}{l}\text { lodine } \\
\text { (in iodine-insufficient areas) }\end{array}$ & $200 \mu \mathrm{g}$ & $200 \mu \mathrm{g}$ \\
\hline Iron & $27-30 \mathrm{mg}$ & $\begin{array}{l}\text { Routine supplementation after BS is recommended } \\
\text { to achieve correct hemoglobin and ferritin levels. }\end{array}$ \\
\hline Vitamin BI2 & $2.6 \mathrm{mg}$ & $\begin{array}{l}\text { Supervised regular supplements to keep levels } \\
\text { within the normal range. }\end{array}$ \\
\hline Calcium & $\mathrm{I}, 000-1,300 \mathrm{mg}$ & Routine supplements after BS, ie, I,200-I,500 mg. \\
\hline Vitamin D & $200-400 \mathrm{UI}$ & $\begin{array}{l}\text { Routine supplements to maintain } 25(\mathrm{OH}) \text {-vitamin D } \\
\text { levels above } 20-30 \mathrm{ng} / \mathrm{dL} \text {. }\end{array}$ \\
\hline Vitamin A & $770 \mu \mathrm{g}$ & $\begin{array}{l}\text { The same as in pregnant women in general. } \\
\text { Supplements should be used routinely after all BPD } \\
\text { procedures and in some cases after RYGB. }\end{array}$ \\
\hline
\end{tabular}

Abbreviations: BS, bariatric surgery; BPD, biliopancreatic diversion; RYGB, Roux-en-Y gastric bypass. 
not necessary, and enteral approach is preferred. For instance, there were $7.7 \%$ of patients requiring oral protein supplements. ${ }^{7}$ Hypoalbuminemia has also been reported during pregnancy, apparently with no clinical consequences. ${ }^{28}$

Standardized management of nutritional deficiencies in the case of a pregnancy occurring after BS is documented, so guidelines for screening and treatment are usually the same as in the conventional BS adjustment, but with special attention to the specific needs during normal pregnancy. In this regard, a complete blood test, including blood count, ferritin, B12, and fat-soluble vitamins, should be performed at least once in each trimester, especially if the procedure included malabsorptive weight loss techniques.

\section{Complications during pregnancy}

The prevalence of GDM varies depending on the population studied and the criteria used for its definition. In any case, a clear increase (10\%-100\%) has been observed worldwide over the last 20 years. ${ }^{29}$ The linear relationship between obesity and diabetes entails an increase in the incidence of GDM of up to three-fold with increasing BMI. ${ }^{30-33}$ Accordingly, numerous studies have reported a reduction in the rate of GDM following the evident weight loss occurring after BS $(0 \%-8.9 \%$ in pregnancies after BS versus $1.6 \%-20.8 \%$ in the control group). However, there were no statistically significant differences in the prevalence of GDM when women with similar BMI were compared. ${ }^{6-8,10-12}$

It is worth noting that not all publications explicitly describe how they screened for the presence of GDM. In fact, this is still a matter of debate, since the anatomical alterations secondary to BS themselves may lead to a poor tolerance of oral glucose overloads, absorption modifications, and changes in the preestablished timings for evaluating the response, making the traditional screening methods less reliable in this particular population.

Gestational hypertension is the most frequent cause of pregnancy-associated hypertensive disorders (PAHD), which affect around 6\%-17\% of nulliparous women and $2 \%-4 \%$ of multiparous women. ${ }^{34}$ Obesity is a well-known associated risk factor for developing this complication, entailing a two to three-fold increased risk for hypertension and preeclampsia in women with a BMI $>30 \mathrm{~kg} / \mathrm{m}^{2} \cdot{ }^{31,35,36}$ The incidence of pregnancy-associated hypertension and preeclampsia increases proportionately with maternal BMI, ranging from $1.4 \%$ to $2.4 \%$ in women with normal body weight, and reaching to $3.5 \%-14.5 \%$ in women with morbid obesity. ${ }^{32,37}$ For women who underwent BS, studies regarding the prevalence of PAHD are less consistent. Although the odds ratio for PAHD is two to three times lower in women who underwent surgery compared with women who have not undergone surgery, the incidence of PAHD ranged widely between $0 \%$ in our own Spanish multicentric cohort to $35 \%$ in other studies. ${ }^{4,5,7,9-11,38}$ In the series reported by Bennett et al, ${ }^{38}$ there was a significantly lower incidence of hypertension in women who had undergone BS (2.5\% of cases), compared with that reported in obese women who were managed conservatively (13\% of patients). The same occurred for the prevalence of preeclampsia: $3 \%$ in women who underwent BS versus $15 \%$ in the control group. In another study, the incidence of PAHD was $16.5 \%$ in the study group, compared with $31.9 \%$ in the control group, which was composed of the same women but with evaluations from a previous pregnancy, ie, before undergoing BS. ${ }^{11}$ However, in the cohort study by Kjaer et al, ${ }^{6}$ no differences were found in the rate of preeclampsia among women who had undergone BS and those who had not. Likewise, in the small study by Patel et al, ${ }^{7}$ which evaluated 26 pregnant women after undergoing laparoscopic RYGB surgery, there were no differences in rates of PAHD compared with controls; in addition, PAHD was similar in pregnancies that occurred "early" ( $<12$ months) versus "later" ( $>18$ months) after BS. Some studies even reported a higher prevalence of hypertension in operated women, but in these cases there were up to three times more cases of $\mathrm{BMI}>30 \mathrm{~kg} / \mathrm{m}^{2}$ than in the control group. ${ }^{4}$ Taking all this data into account, in a recent meta-analysis, the authors concluded that the risk of preeclampsia seems to reduce by about approximately half in women who underwent BS. ${ }^{39}$

Finally, various gastrointestinal complications may develop during pregnancy because of the bariatric procedure itself, and although these complications are not frequent, they may be severe and entail a high morbidity. The associated risk factors are not fully elucidated, and diagnosis may be frequently delayed because symptoms are commonly masked due to the usual malaises that occur during normal pregnancy (mainly abdominal pain, nausea, and vomiting). In a systematic review, 20 cases required urgent abdominal surgery during pregnancy, most of them due to internal hernia after laparoscopic RYGB, and five neonatal and three maternal deaths were reported. ${ }^{40}$ In another more recent study, however, 23 pregnant women underwent urgent surgery due to internal hernias, but survival rates reached $100 \%$ for mother and fetuses, and there were no severe complications. ${ }^{41}$

\section{Fetal loss and perinatal deaths}

Spontaneous abortion may occur in around $10 \%-20 \%$ of general pregnancies, and controversy exists regarding the 
potential influence of obesity on this rate. In general, obesity is usually considered as a risk factor for abortion; in this regard, the risk increases proportionately to $\mathrm{BMI}^{42,43}$ and decreases following an optimal conservative or surgical weight loss. ${ }^{27,44,45}$ However, most of the evidence comes only from retrospective studies, so conclusions should be carefully derived.

Maternal obesity is also associated with an increase in perinatal mortality; in fact, once again, this increase parallels maternal BMI values. In this regard, in three large studies performed in developed countries, there was a 1.4-2.6 increased risk of perinatal loss in obese women in comparison to controls. ${ }^{31,46}$ In the case of pregnant women with previous history of $\mathrm{BS}$, increased intrauterine and neonatal mortality was paradoxically found, in comparison to control morbidly obese women $(1.7 \%$ versus $0.7 \%$, odds ratio: 2.39 ; 95\% confidence interval: $0.98-5.85, P=0.06)$. However, subsequent subanalysis for each individual outcome did not confirm these differences, and the absolute number of adverse events was low. ${ }^{12}$ Similarly, larger cohort studies reported no differences in perinatal or neonatal mortality between women with previous BS and the control group. ${ }^{6,47}$ In addition, in a study with no control group, Sheiner et $\mathrm{al}^{9}$ reported that the incidence of perinatal mortality in operated pregnant women was $0.89 \%$, regardless of the time that had elapsed between BS and pregnancy (less than or more than 12 months).

Concerning the rate of spontaneous abortions, there are few studies that specifically address this issue, but the rate seems to be somewhat higher than in general population, ranging between $23 \%$ and $38.9 \% .^{11,19,27}$ In our own multicentric cohort, however, intrauterine fetal death occurred in $3.57 \%$ of cases, and the overall rate of fetal loss was $17.9 \%{ }^{5}$

\section{Peripartum issues}

Several observational studies have reported an increased rate of intrapartum complications in women with prior BS. Specifically, prolonged delivery, failure in the induction period, and failure in the efficacy of epidural anesthesia have all been described. ${ }^{48-50}$ For the effect on preterm delivery, results from different studies have been rather controversial. In this regard, in a recent meta-analysis, the rate of spontaneous preterm delivery was similar between obese women and controls; however, induced preterm delivery was in fact more frequent in the former, probably due to the associated comorbidities involved in these cases, such as GDM and PAHD. ${ }^{51}$

Reports of the follow-up of pregnant women with prior BS describe variable incidences of preterm delivery, but all below 10\% (range 1.9\%-9.7\%). Furthermore, most series show no differences regarding this adverse outcome between women who underwent BS and those who did not, ${ }^{12}$ although, in some cases, an overall lower mean gestational age was documented in operated women. ${ }^{12,52}$ Several other studies without a control group found no differences in the rate of preterm delivery regarding the type of bariatric procedure, or the time lapse between surgery and conception., ${ }^{4,9,10}$ The study by Roos et al, ${ }^{47}$ however, did find a greater incidence of preterm delivery in women who had undergone BS in comparison to the control group: $9.7 \%$ versus $6.7 \%$; interestingly, women with lower BMI (below $30 \mathrm{~kg} / \mathrm{m}^{2}$ ) were the ones with a greater incidence of this outcome.

As previously outlined, obesity is a major risk factor for the need for C-sections, with this risk increasing for higher BMI values. For women with prior BS, however, rates for $\mathrm{C}$-sections have been variable across the literature. For instance, in several recent studies, there were no statistically significant differences in rates of $\mathrm{C}$-sections between operated women and BMI-matched controls, or between the operated group and conservatively managed obese women. Rates for $\mathrm{C}$-sections in these operated women ranged between $18.3 \%$ and $60 \%$, while the rate in the control group was between $14.4 \%$ and $28.7 \%$. $^{4,6,52}$ There have been some further studies reporting that BS was a clear risk factor for $\mathrm{C}$-section, even after adjusting for other potential confounding factors. ${ }^{9}$ A French study including 24 pregnancies following RYGB surgery (exposed group) were compared with two different control groups: a normal BMI group and a group of 120 pregnancies matched by age, parity, and pregnancy BMI. The study showed increased numbers of reduced birth weight and C-section in the exposed group. ${ }^{13}$ There has also been several attempts to try to elucidate if this is due to a potential underlying cause involving the specific bariatric technique performed, or the period of time between BS and pregnancy, but no definite conclusion has been reached yet. ${ }^{4,9,10}$ In our own population, $\mathrm{C}$-sections were performed in $19.4 \%$ of cases, but we did not observe any association with the type of bariatric technique performed. ${ }^{5}$ Finally, obstetric outcomes were compared in another retrospective case-control study with 427 obese women, 13 of whom underwent $\mathrm{AGB}$ and 414 who did not. This study has shown a lower incidence of adverse obstetric outcomes in those in whom AGB was performed compared with those who did not undergo $\mathrm{AGB}$, including a lower rate of $\mathrm{C}$-section in the operated group. ${ }^{15}$ Similarly, Patel et al, ${ }^{7}$ in a populationbased study comparing 259 pregnancies after BS with a normal pregnant population group, have found that previous BS was not associated with adverse perinatal outcomes. ${ }^{19}$ 
However, in this study, only $10.7 \%$ of the operated women remained obese before pregnancy. ${ }^{14}$

Despite these controversial results, there is no presumable physiopathologic reason to hypothesize that $\mathrm{C}$-sections could be more frequent after BS, and understanding this increased rate is somewhat difficult. Several underlying reasons have been suggested to explain this increased rate of C-sections, including a history of a prior C-section, which is the most relevant issue, but also other variables such as maternal obesity, maternal choice, clinicians' preconceptions regarding obstetric risk in obese women, and fetal positioning, among others. In fact, very few studies describe the specific reason for performing $\mathrm{C}$-sections in their results. Therefore, a thorough and complete objective evaluation should be carried out in these patients, balancing the risks and benefits for implementing this type of delivery, so as to be able to rationally recommend the best delivery approach for women with a prior history of $\mathrm{BS}$.

\section{Fetal outcomes}

Maternal obesity has long been associated with an increased rate of large-for-gestational-age (LGA) newborns, while being a protective factor for small-for-gestational-age (SGA) infants, even after adjusting for other maternal comorbidities..$^{15,31,53}$ In addition, weight gain during pregnancy was found to positively correlate with the newborn's body weight. ${ }^{54}$ This influence of maternal weight on neonatal weight is important at birth time, but also, and probably most importantly, there is a great amount of scientific evidence supporting that it significantly influences intrauterine fetal development, portending an increased risk of overweight and obesity during adolescence and adulthood. ${ }^{55-57}$

However, women with prior BS have been observed to have a lower rate of LGA newborns compared with nonoperated control obese women (ranging between 1.2\% and $7.3 \%$ of cases). $5,11,12,27,47,52$ In fact, in recent years, many studies have reported that women who get pregnant after BS tend to deliver newborns with an overall lower body weight, and a higher rate of SGA infants (5.2\%-27.8\%), in comparison to nonoperated women. ${ }^{5,11,12,27,47,52}$ In a retrospective study by Kjaer et al, ${ }^{6} 339$ women with a singleton delivery after BS were matched by pregnancy BMI, maternal age, parity, and date of delivery with 1,277 non-operated women. They found that babies born after maternal BS had lower birth weight, lower gestational age, 3.3-times lower risk of LGA, and 2.3-times higher risk of SGA than infants born to matched women without BS. In addition, a recent retrospective, matched-control cohort study has compared birth weights of babies born to women with pregnancies before and after RYGB surgery. ${ }^{54}$ Interestingly, the authors communicated that women who had undergone RYGB had a significantly lower risk for having an LGA newborn, but also a significantly increased risk for delivering an SGA neonate, than nonoperated women closely matched by age and BMI before pregnancy. ${ }^{54}$

The variability and heterogeneity of the incidence reported may be due to differences in the definition of SGA, and the type of bariatric procedure performed, among other reasons. However, a full explanation for this higher rate of SGA infants after BS is still unknown. A possible mechanism could be that women with prior BS may present a higher risk for nutrient deficiency, and thus, favor fetal deficiencies. However, the negative influence of this issue in the longterm follow-up still deserves further investigation. 5,11,12,27,47,52 However, the number of malabsorptive techniques performed has significantly reduced over the last couple of years, allowing other surgical approaches, with less adverse effects, to gain popularity; thus, a reduction in the incidence of SGA infants may be expected.

There are also some publications reporting the outcomes of the offspring of women who had previously undergone BS. For instance, Smith et $\mathrm{al}^{58}$ performed an interesting study in which they hypothesized that maternal weight loss due to BS could indeed affect the intrauterine environment and, consequently, affect the potential risk of children developing obesity during life. They observed that offspring born after maternal RYGB surgery exhibited increased insulin sensitivity and improved lipid profiles compared with offspring born before maternal surgery, including a lower risk for obesity, even though neonatal body weight was lower and many women were still obese when they conceived. ${ }^{59}$ This finding suggests that intrauterine environment may be even more relevant for pregnancies in women with previous $\mathrm{BS}$, because of its influence on epigenetics and subsequent development of obesity and other cardiovascular risk factors. ${ }^{58}$ In fact, Kral et al ${ }^{59}$ evaluated the rates of overweight and obesity in children born to mothers with previous BS and found that they were lower. In another study, the authors investigated the body weight of siblings born of the same mother before and after BPD for obesity. At 1 and 6 years, the body weight was described as similar in both groups. However, at 12 years of age, a higher percentage of those born before BPD were considered overweight. The main strength of this study is that the influences of the genetic pattern and environmental and educational factors were minimized. ${ }^{60}$ In the same way, another study performed with 15 mothers 
with siblings born before and after BPD with duodenal switch has shown that the hostile dysmetabolic intrauterine environment modulates genotype and gene expression levels in the offspring, promoting the development of obesity and subsequent cardiometabolic risk factors in the offspring born from obese women. ${ }^{61}$

Moreover, in another large and more recent study in which BMI was considered only until the age of 10 years in the children of women with prior BS, there were no differences or any specific association with pregestational maternal BMI. The authors acknowledged that they could not establish definite conclusions regarding the effect of BS in the offspring's long-term body weight. ${ }^{62}$ Likewise, in a Swedish cohort of women with at least one child born before and after BS, no differences in BMI score were observed between siblings when they arrive at preschool age. ${ }^{63}$ Therefore, further longterm studies are needed to better understand this issue.

Finally, there are several reports of an increased incidence of congenital anomalies in children born after maternal BS. In this regard, the main alteration concerns neural tube defects, but cardiac abnormalities may also occur, particularly septal defects, as well as cleft lip and cleft palate, anorectal atresia, hydrocephalus, and limb shortening. ${ }^{64}$ This increased incidence of adverse congenital outcomes conveys an added difficulty to a correct identification of up to $15 \%$ of normal structures during the ultrasound at week 20. In fact, the greater the maternal BMI is, the less visible the fetal structures may be, entailing a potential risk of an increased rate of unidentified congenital malformations and defects. ${ }^{65,66}$

In studies comparing the outcomes of operated pregnant women with those of a control group, in general, there were no differences in the prevalence of congenital malformations, although rates in both groups were diverse, ranging from 0 to $5.1 \%{ }^{7,9,12}$ Conversely, in other studies without a control group, the prevalence was also variable, but low $(0 \%-2.2 \%) .^{4,5,27,67}$ In addition, there have been several publications of isolated case reports or even case series, in which specific neonatal diseases were reported in association with maternal nutrient deficiencies. Even though these cases are rare, they may be frequent in the setting of malabsorptive procedures, or poor compliance with medical follow-up and nutritional supplements. In this regard, the most frequently described maternal micronutrient deficiency is that of folic acid, which entails a high risk of fetal neural tube defects. ${ }^{68}$ Moreover, there have been case reports of maternal and fetal hypercoagulability due to vitamin $\mathrm{K}$ deficiency following $\mathrm{BPD}$, ophthalmic and renal malformations due to severe maternal and fetal vitamin A deficiency, and megaloblastic anemia due to vitamin B12 deficiency. ${ }^{69-71}$

\section{Conclusion}

Pregnancy after BS is safe, both for the mother and for the fetus. However, an optimal and prudent waiting period between BS and pregnancy should be individually advised, at least until body weight stabilizes and potential nutritional deficiencies are overcome with targeted treatment. No significant differences in maternal and fetal outcomes have been found between pregnancies occurring before or after 12 months of BS. However, the number of cases reported in each study is too small to be able to draw definite conclusions. Nutritional deficiencies that may be present before BS usually exacerbate during pregnancy, so it is highly recommended that strict medical monitoring and correct micronutrient and supplement compliance are observed. Available scientific evidence suggests that the risk of GDM and PAHD significantly decreases in women who previously underwent $\mathrm{BS}$, in comparison to morbidly obese patients who were managed conservatively, and the risk may even be like that of women with a similar BMI in whom surgery was not performed. There is still insufficient evidence to suggest that $\mathrm{BS}$ reduces the risk of $\mathrm{C}$-sections. On the other hand, there is enough data advising that women with prior BS have an increased risk of SGA newborns in comparison to nonoperated obese pregnant women, but the relevance of this finding in the long-term follow-up still deserves further investigation. ${ }^{72}$

\section{Acknowledgments}

We acknowledge the Endocrinology and Nutrition Spanish Society (SEEN), and specially its Obesity Study Group (GOSEEN), for supporting this work. We also acknowledge Dr Ana M. Ramos-Leví and Dr Carolina López for their valuable help in the preparation of this manuscript.

\section{Disclosure}

The authors report no conflicts of interest in this work.

\section{References}

1. Nuthalapaty FS, Rouse DJ. The impact of obesity on obstetrical practice and outcome. Clin Obstet Gynecol. 2004;47(4):898-913.

2. Martínez-Ortega AJ, Aliaga-Verdugo A, Pereira-Cunill JL, et al. Intraluminal/endoscopic procedures in the treatment of obesity. Endocrin Nutr. 2014;61(5):264-273.

3. Lecube A, De Hollanda A, Calañas A, et al. Trends in bariatric surgery in Spain in the twenty-first century: baseline results and 1-month follow up of the RICIBA, a National Register. Obes Surg. 2015;26(8):1836-1842.

4. Wax JR, Cartin A, Wolf R, Lepich S, Pinette MG, Blackstone J. Pregnancy following gastric bypass for morbid obesity: effect of surgeryto-conception interval on maternal and neonatal outcomes. Obes Surg. 2008;18(12):1517-1521. 
5. González I, Rubio MA, Cordido F, et al. Maternal and perinatal outcomes after bariatric surgery: a Spanish multicenter study. Obse Surg. 2015; 25(3):436-442.

6. Kjaer MM, Lauenborg J, Breum BM, Nilas L. The risk of adverse pregnancy outcome after bariatric surgery: a nationwide register-based matched cohort study. Am J Obstet Gynecol. 2013;208(6):464.e1-e5.

7. Patel JA, Patel NA, Thomas RL, Nelms JK, Colella JJ. Pregnancy outcomes after laparoscopic Roux-en-Y gastric bypass. Surg Obes Relat Dis. 2008; 4(1):39-45.

8. Dao T, Kuhn J, Ehmer D, Fisher T, McCarty T. Pregnancy outcomes after gastricbypass surgery. Am J Surg. 2006;192(6):762-766.

9. Sheiner E, Edri A, Balaban E, Levi I, Aricha-Tamir B. Pregnancy outcome of patients who conceive during or after the first year following bariatric surgery. Am J Obstet Gynecol. 2011;204(1):50.e1-e6.

10. Sheiner E, Balaban E, Dreiher J, Levi I, Levy A. Pregnancy outcome in patients following different types of bariatric surgeries. Obes Surg. 2009;19(9):1286-1292.

11. Aricha-Tamir B, Weintraub Y, Levi I, Sheiner E. Downsizing pregnancy complications: a study of paired pregnancy outcomes before and after bariatric surgery. Surg Obes Relat Dis. 2012;8(4):434-439.

12. Johansson $\mathrm{K}$, Cnattingius S, Näslund I, et al. Outcomes of pregnancy after bariatric surgery. $N$ Eng J Med. 2015;372(9):814-824.

13. Santulli P, Mandelbrot L, Facchiano E, et al. Obstetrical and neonatal outcomes of pregnancies following gastric bypass surgery: a retrospective cohort study in a French referral center. Obes Surg. 2010;20(11): 1501-1508

14. Sheiner E, Levy A, Silverberg D, et al. Pregnancy after bariatric surgery is not associated with adverse perinatal outcome. Am J Obstet Gynecol. 2004;190(5):1335-1340.

15. Ducarme G, Revaux A, Rodrigues A, Aissaoui F, Pharisien I, Uzan M. Obstetric outcome following laparoscopic adjustable gastric banding. Int J Gynaecol Obstet. 2007;98(3):244-247.

16. Lier HØ, Biringer E, Stubhaug B, Tangen T. The impact of preoperative counseling on postoperative treatment adherence in bariatric surgery patients: a randomized controlled trial. Patient Educ Couns. 2012;87(3): 336-342.

17. Dell'Agnolo CM, Carvalho MD, Pelloso SM. Pregnancy after bariatric surgery: implications for mother and newborn. Obes Surg. 2011;21(6): 699-706.

18. Wittgrove AC, Jester L, Wittgrove P, Clark GW. Pregnancy following gastric bypass for morbid obesity. Obes Surg. 1998;8(4):461-464.

19. Bebber FE, Rizzolli J, Casagrande DS, et al. Pregnancy after bariatric surgery: 39 pregnancies follow-up in a multidisciplinary team. Obes Surg. 2011;21(10):1546-1551.

20. Gadgil MD, Chang HY, Richards TM, et al. Laboratory testing for and diagnosis of nutritional deficiencies in pregnancy before and after bariatric surgery. J Womens Health (Larchmt). 2014;23(2): 129-137.

21. Printen KJ, Scott D. Pregnancy following gastric bypass for the treatment of morbid obesity. Am Surg. 1982;48(8):363-365.

22. Gurewitsch E, Smith-Levitin M, Mack J. Pregnancy following gastric bypass surgery for morbid obesity. Obstet Gynecol. 1996;88(4 Pt 2): 658-661

23. Mechanick JI, Youdim A, Jones DB, et al. Clinical practice guidelines for the perioperative nutritional, metabolic, and nonsurgical support of the bariatric surgery patient - 2013 update: cosponsored by American Association of Clinical Endocrinologists, The Obesity Society, and American Society for Metabolic \& Bariatric Surgery. Endocr Pract. 2013;19(2):337-372.

24. Devlieger R, Guelinckx I, Jans G, Voets W, Vanholsbeke C, Vansant G. Micronutrient levels and supplement intake in pregnancy after bariatric surgery: a prospective cohort study. PLoS One. 2014;9(12):e114192.

25. Werler MM, Lammer EJ, Rosenberg L, Mitchell AA. Maternal vitamin A supplementation in relation to selected birth defects. Teratology. 1990; 42(5):497-504.

26. Dudas Y, Czeizel AE. Use of 6,000 UI vitamin A during early pregnancy without teratogenic effect. Teratology. 1992;45(4):335-336.
27. Friedman D, Cuneo S, Valenzano M, et al. Pregnancies in an 18-year follow-up after biliopancreatic diversion. Obes Surg. 1995;5(3): 308-313.

28. MeadNC,SakkatosP, Sakellaropoulos GC,Adonakis GL, Alexandrides TK, Kalfarentzos F. Pregnancy outcomes and nutritional indices after 3 types of bariatric surgery performed at a single institution. Surg Obes Relat Dis. 2014;10(6):1166-1173.

29. Ferrara A. Increasing prevalence of gestational diabetes mellitus. Diabetes Care. 2007;30(supp 2):S141-S146.

30. Ricart W, López J, Mozas J. Potential impact of American Diabetes Association (2000) criteria for diagnosis of gestational diabetes mellitus in Spain. Diabetologia. 2005;48(6):1135-1141.

31. Sebire NJ, Jolly M, Harris JP, et al. Maternal obesity and pregnancy outcome: a study of 287,213 pregnancies in London. Int J Obes Relat Metab Disord. 2001;25(8):1175-1182.

32. Callaway LK, Prins JB, Chang AM, McIntyre HD. The prevalence and impact of overweight and obesity in an Australian obstetric population. Med J Aust. 2006;184(2):56-59.

33. Weiss JL, Malone FD, Emig D, et al. Obesity, obstetric complications and cesarean delivery rate - a population-based screening study. Am J Obstet Gynecol. 2004;190(4):1091-1097.

34. Rosas M, Lomelí C, Mendoza-González C, et al. Hypertension in pregnancy. Arch Cardiol Mex. 2008;78(Suppl 2):104-108.

35. American College of Obstetricians and Gynecologists. ACOG Committee opinion no. 549: obesity in pregnancy. Obstet Gynecol. 2013;121(1): 213-217.

36. Paré E, Parry S, McElrath TF, Pucci D, Newton A, Lim KH. Clinical risk factors for preeclampsia in the 21st century. Obstet Gynecol. 2014; 124(4):763-770.

37. Cedergren MI. Maternal morbid obesity and the risk of adverse pregnancy outcome. Obstet Gynecol. 2004;103(2):219-224.

38. Bennett WL, Gilson MM, Jamshidi R, et al. Impact of bariatric surgery on hypertensive disorders in pregnancy: retrospective analysis of insurance claims data. BMJ. 2010;340:c1662.

39. Galazis N, Docheva N, Similis C, Nicolaides KH. Maternal and neonatal outcomes in women undergoing bariatric surgery: a systematic review and meta-analysis. Eur J Obstet Gynecol Reprod Biol. 2014;181: 45-53.

40. Maggard MA, Yermilov I, Li Z, et al. Pregnancy and fertility following bariatric surgery: a systematic review. JAMA. 2008;300(19): 2286-2296.

41. Gudbrand C, Andreasen LA, Boilesen AE. Internal hernia in pregnant women after gastric bypass: a retrospective register-based cohort study. Obes Surg. 2015;25(12):2257-2262.

42. Wang JX, David MJ, Norman RJ. Obesity increases the risk of spontaneus abortion during infertiliy treatment. Obes Res. 2002;10(6):551-554.

43. Lashen H, Fear K, Sturdee DW. Obesity is associated with increased risk of first trimester and recurrent miscarriage: matched case-control study. Hum Reprod. 2004;19(7):1644-1646.

44. Clark AM, Thornley B, Tomlinson L, Galletley C, Norman RJ. Weight loss in obese infertile women results in improvement in reproductive outcome for all forms of fertility treatment. Hum Reprod. 1998; 13(6):1502-1505.

45. Bilenka B, Ben-Shlomo I, Cozacov C, Gold CH, Zohar S. Fertility, miscarriage and pregnancy after vertical banded gastroplasty operation for morbid obesity. Acta Obstet Gynecol Scand. 1995;74(1):42-44.

46. Cnattingius S, Bergstrom R, Lipworth L, Kramer MS. Prepregnancy weight and the risk of adverse pregnancy outcomes. NEng J Med. 1998; 338(3):147-152.

47. Roos N, Neovius M, Cnattingius S, et al. Perinatal outcomes after bariatric surgery: nationwide population based matched cohort study. BMJ. 2013;347:f6460.

48. Nuthalapaty FS, Rouse DJ, Owen J. The association of maternal weight with cesarean risk, labor duration, and cervical dilation rate during labor induction. Obstet Gynecol. 2004;103(3):452-456.

49. Chu SY, Kim SY, Schmid CH, et al. Maternal obesity and risk of cesarean delivery: a meta-analysis. Obes Rev. 2007;8(5):385-394. 
50. Hood DD, Dewan DM. Anesthetic and obstetric outcome in morbidly obese parturients. Anesthesiology. 1993;79(6):1210-1218.

51. McDonald SD, Han Z, Mulla S, Beyene J; Knowledge Synthesis Group. Overweight and obesity in mothers and risk of preterm birth and low birth weight infants: systematic review and meta analyses. BMJ. 2010;341:c3428.

52. Josefsson A, Blomberg M, Bladh M, Frederiksen SG, Sydsjö G. Bariatric surgery in a national cohort of women: sociodemographics and obstetric outcomes. Am J Obstet Gynecol. 2011;205(3):206.e1-e8.

53. Eastman NJ, Jackson E. Weight relationships in pregnancy. I. The bearing of maternal weight gain and pre-pregnancy weight on birth weight in full term pregnancies. Obstet Gynecol Surv. 1968;23(11):1003-1025.

54. Adams TD, Hammoud AO, Davidson LE, et al. Maternal and neonatal outcomes for pregnancies before and after gastric bypass surgery. Int $J$ Obes (Lond). 2015;39(4):686-694.

55. Love EJ, Kinch RA. Factors influencing the birth weight in normal pregnancy. Am J Obstet Gynecol. 1965;91:342-349.

56. Oken E, Gillman MW. Fetal origins of obesity. Obes Res. 2003;11(4): 496-506.

57. Curhan GC, Willett WC, Rimm EB, Spiegelman D, Ascherio AL, Stampfer MJ. Birth weight and adult hypertension, diabetes mellitus and obesity in U.S. men. Circulation. 1996;94(12):3246-3250.

58. Smith J, Cianflone K, Biron S, et al. Effects of maternal surgical weight loss in motherson intergenerational transmission of obesity. J Clin Endocrinol Metab. 2009;94(11):4275-4283.

59. Kral JG, Biron S, Simard S, et al. Large maternal weight loss from obesity surgery prevents transmission of obesity to children who were followed for 2 to 18 years. Pediatrics. 2006;118(6):e1644-e1649.

60. Barisione M, Carlini F, Gradaschi R, Camerini G, Adami GF. Body weight at developmental age in siblings born to mothers before and after surgically induced weight loss. Surg Obes Relat Dis. 2012;8(4):387-391.

61. Guénard F, Lamontagne M, Bossé Y, et al. Influences of gestational obesity on association between genotypes and gene expression levels in offspring following maternal gastrointestinal bypass surgery for obesity. Plos One. 2015;10(1):e0117011.
62. Willmer M, Berglind D, Thorkild I, et al. Surgically induced interpregnancy weight loss and prevalence of overweight and obesity in offspring. PLoS One. 2013;8(12):e82247.

63. Berglind D, Willmer M, Näslund E, Tynelius P, Sørensen TI, Rasmussen F. Differences in gestational weight gain between pregnancies before and after maternal bariatric surgery correlate with differences in birth weight but not with scores on the body mass index in early childhood. Pediatr Obes. 2014;9(6):427-434.

64. Stothard KG, Tennant PW, Bell R, Rankin J. Maternal overweight and obesity and the risk of congenital anomalies: a systematic review and meta-analysis. JAMA. 2009;301(6):636-650.

65. Wolfe HM, Sokol RJ, Martier SM, Zador IE. Maternal obesity: a potential source of error in sonographic prenatal diagnosis. Obstet Gynecol. 1990; 76(3 Pt 1):339-342.

66. Hendler I, Blackwell SC, Bujold E, et al. Suboptimal second-trimester ultrasonographic visualization of the fetal heart in obese women: should we repeat the examination? J Ultrasound Med. 2005;24(9): 1205-1209.

67. Sapre N, Munting K, Pandita A, Stubbs R. Pregnancy following gastric bypass surgery: what is the expected course and outcome? NZMed J.2009; 122(1306):33-42.

68. Pelizzo G, Calcaterra V, Fusillo M, et al. Malnutrition in pregnancy following bariatric surgery: three clinical cases of fetal neural defects Nutr J. 2014;13:59.

69. Bersani I, De Carolis MP, Salvi S, Zecca E, Romagnoli C, De Carolis S. Maternal-neonatal vitamin $\mathrm{K}$ deficiency secondary to maternal biliopancreatic diversion. Blood Coagul Fibrinolysis. 2011;22(4):334-336.

70. Ocón J, Sallán L. Maternal and neonatal complications in a pregnant woman with biliopancreat diversion. Nutr Hosp. 2010;25(1): $120-122$.

71. Campbell CD, Ganesh J, Ficicioglu C. Two newborns with nutritional vitamin B12 deficiency: challenges in newborn screening for vitamin B12 deficiency. Haematologica. 2005;90(12):e119-e121.

72. García-Luna PP, González I. Pregnancy after bariatric surgery: what should we tell our patients? Endoc Nutr. 2014;61(2):65-67.
International Journal of Women's Health

\section{Publish your work in this journal}

The International Journal of Women's Health is an international, peerreviewed open-access journal publishing original research, reports, editorials, reviews and commentaries on all aspects of women's healthcare including gynecology, obstetrics, and breast cancer. The manuscript management system is completely online and includes

\section{Dovepress}

a very quick and fair peer-review system, which is all easy to use. Visit http://www.dovepress.com/testimonials.php to read real quotes from published authors. 